\title{
Energetic Materials Research at Ludwig Maximilian University of \\ Munich (LMU)
}

Review

Article

\author{
Thomas M. Klapötke
}

\author{
LMU Munich
}

\section{Key Words:}

Energetic materials, explosives, propellants

\section{Corresponding Author:}

Thomas M. Klapötke,

LMU Munich, +49 89218077491 , tmk@cup.uni-muenchen.de

\begin{abstract}
In this contribution, selected aspects of the energetic materials research which is being undertaken at Ludwig-Maximilian University (LMU) Munich will be described. The main areas of interest that are discussed within this review are high explosives and propellant formulations. This review on new energetic materials is not exhaustive in scope but focuses on the most recent developments of new explosives and oxidizers for propellant formulations at LMU Munich. Naturally, the cited literature also emphasizes the work in Munich and does not include work that has been carried out elsewhere. The work of other research groups is included in the references of the original literature cited at the end of the review. In this contribution, selected aspects of the energetic materials research which is being undertaken at Ludwig-Maximilian University (LMU) Munich will be described. The main areas of interest that are discussed within this review are high explosives and propellant formulations. This review on new energetic materials is not exhaustive in scope but focuses on the most recent developments of new explosives and oxidizers for propellant formulations at LMU Munich. Naturally, the cited literature also emphasizes the work in Munich and does not include work that has been carried out elsewhere. The work of other research groups is included in the references of the original literature cited at the end of the review.
\end{abstract}

\section{INTRODUCTION}

Since the first commercialization of nitroglycerine (NG) in the form of dynamite in 1867 by Alfred Nobel, great strides have been made in increasing the performance of energetic materials but at the same time decreasing their sensitivities. Despite this, military forces continue to rely on traditional energetic materials which are halfcentury old to meet their combat needs. This situation means that new energetic materials must be developed in order to enable advancement beyond the traditional boundaries in the capabilities of energetic materials allowing a transition to the next stage in combat, and to maintain a lethality overmatch with all enemies ${ }^{[1-4]}$.

\section{ENERGETIC MATERIALS}

Energetic materials are most commonly used in either high explosives or propellant formulations. Certain parameters are important in determining the effectiveness of new molecules in propellant formulations, including high densities ( $\rho)$ and a good oxygen balance $(\Omega)$, as well as high detonation/combustion temperatures and high specific impulses $\left(\mathrm{I}_{\mathrm{sp}}\right)$ for rocket propellant formulations, whereas lower combustion temperatures combined with a high force and pressure, in addition to a high $\mathrm{N}_{2} / \mathrm{CO}$ ratio of the reaction gases for gun propellants are desired ${ }^{[5]}$.
Using the heat of explosion (Q), the detonation velocity (D) and the detonation pressure (P) as a measure for the performance of a high explosive, it can clearly be seen in Fig. 1 that since TNT was introduced into service, the performance of chemical explosives has improved substantially.

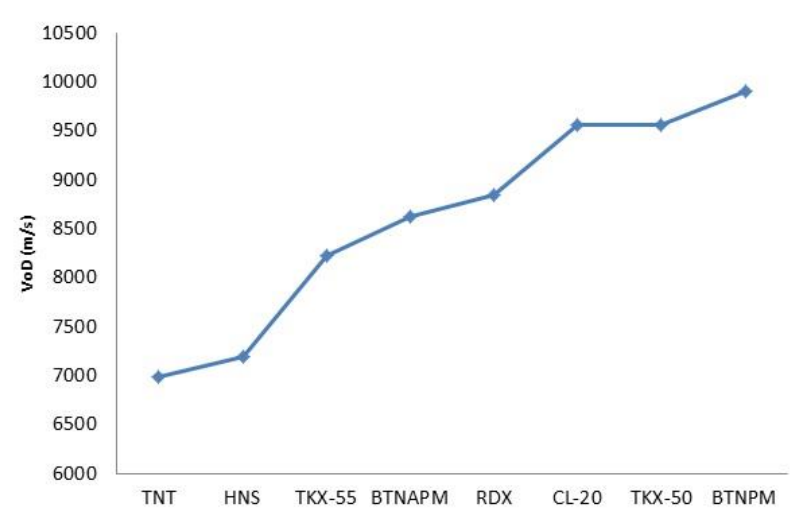

Fig. 1: Detonation velocities (VoD in $\mathrm{m} \mathrm{s}-1)$ of chemical explosives $(\mathrm{TNT}=$ trinitrotoluene, HNS = Hexanitrostilbene, BTNAPM $=$ bis(4-amino-3,5dinitropyrazolyl)methane, RDX = hexogen, CL-20 = hexanitro hexaaza isowurtzitane, TKX-50 = dihydroxylammonium 5,50-bistetrazole-1,10-diolate, BTNPM = bis(3,4,5-trinitropyrazolyl)methane). 
In spite of many years of intensive research, there are only a limited number of possibilities to realize a substantial increase in the performance of conventional C-H-N-O explosives so far. Recent advances in increasing the energy output of energetic materials have come from improved processing, or the inclusion of energetic binders to increase the overall formulation energy. However, only limited success has been achieved in the development of novel energetic materials. One reason for this is that conventional nitramine and nitroaromatic explosives such as trinitro-toluene (TNT), trimethylene-trinitramines (RDX) and other similar molecules share the same three limitations (Table 1):

(i) They are not nitrogen-rich molecules.

(ii) The oxygen-balance is not close to zero.

(iii) Formulations (mixtures of various HEs)

are required to achieve a good oxygen balance.

Table 1: Nitrogen content $(\mathrm{N})$ and oxygen balance $(\Omega)$ of conventional HEs

\begin{tabular}{llll}
\hline & $\mathrm{N} / \%$ & $\Omega\left(\mathrm{CO}_{2}\right) / \%$ & $\Omega(\mathrm{CO}) / \%$ \\
\hline TNT & 18.5 & -73.9 & -24.7 \\
HNS & 18.7 & -67.6 & 0 \\
RDX & 37.8 & -21.6 & 0 \\
\hline
\end{tabular}

Nitrogen-rich molecules are particularly desirable as energetic materials because of the high energy content of $\mathrm{N}-\mathrm{N}$ bonds which is released on formation of $\mathrm{N}_{2}$. The oxygen balance is defined as the percentage of used oxygen that remains - or is needed - after an oxidation reaction has occurred and can therefore be positive - or negative. Materials with an oxygen balance close to zero are typically - but not always - more effective energetic materials, since all of the oxygen is used up in the reaction. An oxygen balance can be modified through choosing appropriate additives to a formulation to bring the overall oxygen balance of the formulation close to zero with respect to $\mathrm{CO}$.

\section{FUTURE ENERGETICS}

Researchers have already reached the energy content limit for $\mathrm{CHNO}$ based molecules. Consequently, new research needs to expand beyond this way of thinking and efforts have to be increased to explore different possible molecular structures and molecular make-up, in order to reach the substantial increase in performance that will be required for future combat systems. Early researches have shown that materials with a high nitrogen content offer many advantages to those with carbon backbones. One of these advantages is the potential for a vastly increased energy content in nitrogen-rich materials ; research into molecules with high nitrogen contents $(>50 \%)$ has shown that these compounds can be the potential candidates for achieving a substantial increase in the available energy. The first generation of high-nitrogen compounds, such as hydrazinium azotetrazolate (HZT) and triamino-guanidinium azotetrazolate (TAGZT) (Fig. 2) [6], did indeed meet the criteria for being nitrogen-rich and proved to be very desirable ingredients in erosion-reduced gun propellants (see Fig. 3). However, due to the unfavourable oxygen balance of such compounds, they are not suitable as energetic fillers in high explosive compositions.
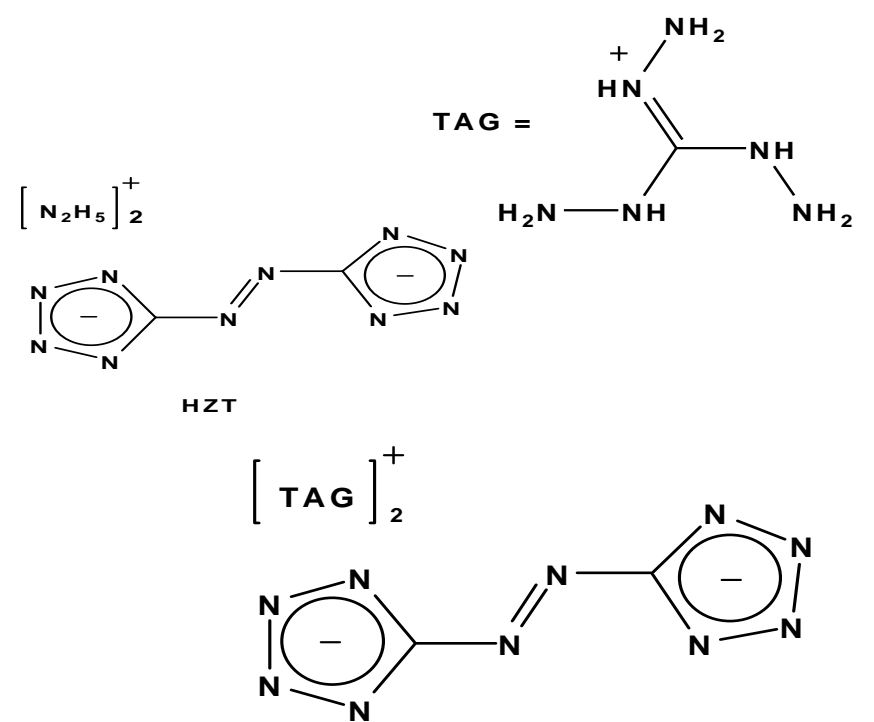

TAGZT

Fig. 2: Chemical Structures of HZT (hydrazinium azotetrazolate) and TAGZT (triaminoguanidinium azotetrazolate).

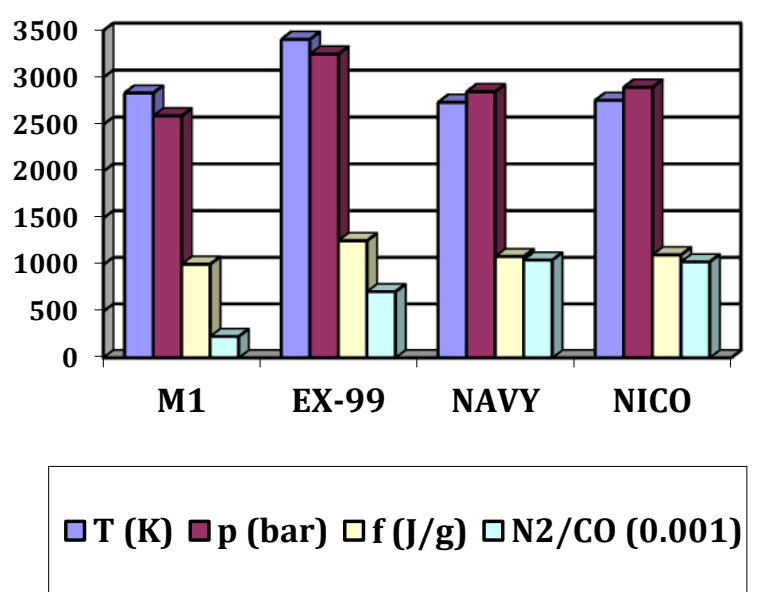

Fig. 3: Gun propellant parameters (for the composition of these materials see Table 2). 
Table 2: Propellant charge compositions

\begin{tabular}{lll}
\hline Propellant charge formulation & Ingredient & amount /\% (mass-\%)
\end{tabular}

\begin{tabular}{|c|c|c|}
\hline \multirow[t]{4}{*}{ M1 } & $\mathrm{NC}(13.25)$ & 86 \\
\hline & 2,4-DNT & 10 \\
\hline & Dibutyl phthalate (DBP) & 3 \\
\hline & Diohenyl amine (DPA) & 1 \\
\hline \multirow[t]{4}{*}{ EX-99 } & RDX & 76 \\
\hline & Cellulose acetate & 12 \\
\hline & $\mathrm{BDNPA} / \mathrm{F}^{\mathrm{a}}$ & 8 \\
\hline & $\mathrm{NC}(13.25)$ & 4 \\
\hline \multirow[t]{6}{*}{ NAVY-high-N } & RDX & 40 \\
\hline & TAGzT & 20 \\
\hline & FOX-12/GUDN & 16 \\
\hline & Cellulose acetate & 12 \\
\hline & $\mathrm{BDNPA} / \mathrm{F}^{\mathrm{a}}$ & 8 \\
\hline & $\mathrm{NC}(13.25)$ & 4 \\
\hline \multirow[t]{6}{*}{$\mathrm{NICO}$} & RDX & 40 \\
\hline & $\mathrm{TAG}_{2}-\mathrm{BT}^{\mathrm{b}}$ & 20 \\
\hline & FOX-12/GUDN & 16 \\
\hline & Cellulose acetate & 12 \\
\hline & BDNPA/F & 8 \\
\hline & $\mathrm{NC}(13.25)$ & 4 \\
\hline
\end{tabular}

a Bis(dinitropropyl)acetal (BDNPA) : Bis(dinitropropyl)formal (BDNPF) $=50: 50$

b $\mathrm{TAG}_{2}-\mathrm{BT}=\left(\mathrm{CN}_{6} \mathrm{H}_{9}\right)_{2}-5,5^{\prime}$-bistetrazolate

The second generation of high-nitrogen compounds such as TKX-50 $0^{[8-13]}$ and BTNPM (bis $3,4,5$ trinitropyrazolyl)methane $)^{[14-15]} \quad$ (Figs. 4 and 5) have improved oxygen balances, and they combine the desirable high nitrogen content with a good oxygen balance. These more suitable for using in high-explosive formulations. Moreover, materials with an oxygen balance close to zero are also suitable as powerful ingredients in solid rocket propellants. An increase in the $I_{s p}$ of only 20 s, would be expected to be able to increase the payload or range by ca. $100 \%$. 

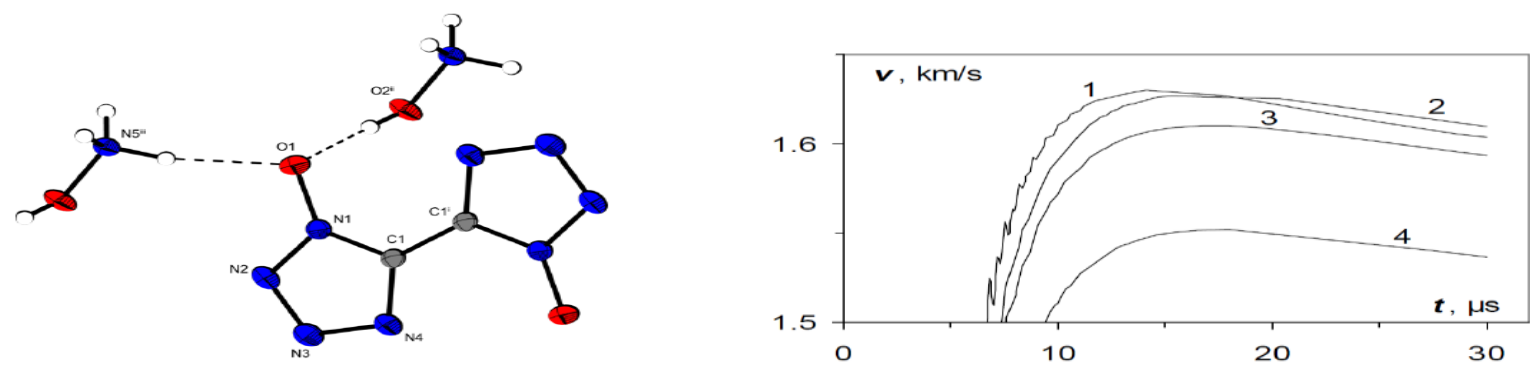

Fig. 4: Structure of TKX-50 (left) and graph showing a comparison of the acceleration of Ta cylindrical layers by TKX-50 (1), HMX (2), MAD-X1 (dihydroxylammonium 3,3'-dinitro-5,5'-bis-1,2,4-triazole-1,1-diolate) and RDX (4) (right).

In case of TKX-50 and BTNPM, the computed and predicted performance values not only exceed the first

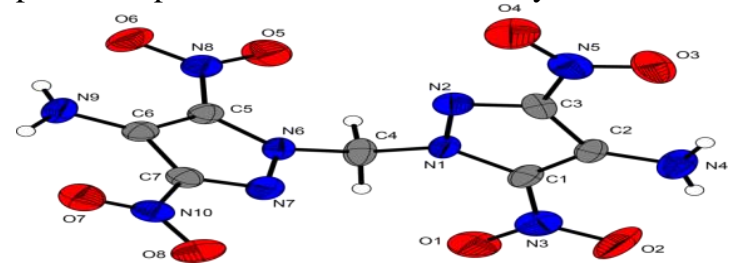

generation of high-nitrogen compounds (e.g. HZT), but also the performance values of RDX (Tab. 3).

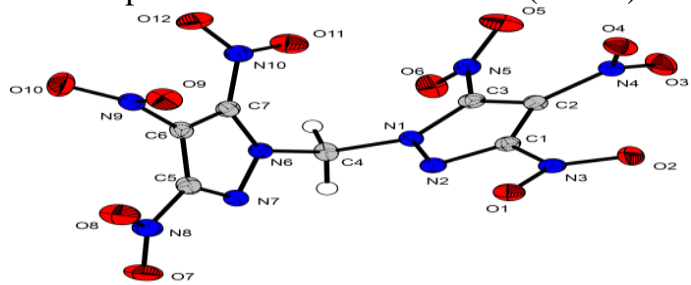

Fig. 5: Structures of BTNAPM (bis(3,5-dinitro-4-aminopyrazolyl)methane) (left) and BTNPM (bis(3,4,5-trinitropyrazolyl)methane) (right).

Table 3: Theoretical performance of modern high explosives.

\begin{tabular}{|c|c|c|c|c|}
\hline & TKX-55 & TKX-50 & BTNAPM & BTNPM \\
\hline Formula & $\mathrm{C}_{16} \mathrm{H}_{4} \mathrm{~N}_{10} \mathrm{O}_{14}$ & $\mathrm{C}_{2} \mathrm{H}_{8} \mathrm{~N}_{10} \mathrm{O}_{4}$ & $\mathrm{C}_{7} \mathrm{H}_{6} \mathrm{~N}_{10} \mathrm{O}_{8}$ & $\mathrm{C}_{7} \mathrm{H}_{2} \mathrm{~N}_{10} \mathrm{O}_{12}$ \\
\hline Molecular Mass & 560.26 & 236.2 & 358.2 & 418.2 \\
\hline \multicolumn{5}{|l|}{$\left[\mathrm{g} \mathrm{mol}^{-1}\right]$} \\
\hline IS [J] & $5[1]$ & 20 & $11[1]$ & $4[1]$ \\
\hline $\mathrm{FS}[\mathrm{N}]$ & $>360[1]$ & 120 & $>360[1]$ & $144[1]$ \\
\hline $\operatorname{ESD}[\mathrm{J}]$ & $1.0[1]$ & 0.1 & $>1[1]$ & $0.1[1]$ \\
\hline $\mathrm{N}[\%]$ & 25.00 & 59.3 & 39.10 & 33.50 \\
\hline$\Omega\left(\mathrm{CO}_{2}\right)[\%]$ & -57.11 & -27.1 & -40.20 & -11.48 \\
\hline $\mathrm{T}_{\text {m.p. }}\left[{ }^{\circ} \mathrm{C}\right]$ & - & --- & - & - \\
\hline $\mathrm{T}_{\mathrm{dec} .}\left[{ }^{\circ} \mathrm{C}\right]$ & $335[1]$ & 221 & $310[1]$ & $205[1]$ \\
\hline \multicolumn{5}{|l|}{ (DSC @ $\left.5^{\circ} \mathrm{C} / \mathrm{min}\right)$} \\
\hline$\rho\left[\mathrm{g} \mathrm{cm}^{-3}\right](@ 298 \mathrm{~K})$ & 1.837 & 1.877 & 1.802 & 1.934 \\
\hline$\Delta_{\mathrm{f}} H^{\circ}\left[\mathrm{kJ} \mathrm{mol}^{-1}\right]$ & 197.6 & 446.6 & 205.1 & 378.6 \\
\hline$\Delta_{\mathrm{f}} H^{\circ}\left[\mathrm{kJ} \mathrm{kg}^{-1}\right]$ & -352.7 & 1890.8 & 655.8 & -976.8 \\
\hline \multicolumn{5}{|l|}{ calcd. (EXPLO5 6.02) } \\
\hline$-\Delta_{\mathrm{ex}} U^{\circ}\left[\mathrm{kJ} \mathrm{kg}^{-1}\right]$ & 4577 & 5984 & 5052 & 6254 \\
\hline $\mathrm{T}_{\mathrm{ex}}[\mathrm{K}]$ & 3532 & 3620 & 3580 & 4570 \\
\hline $\mathrm{p}_{\mathrm{C}-\mathrm{J}}[\mathrm{kbar}]$ & 243 & 408 & 295 & 393 \\
\hline VoD [m s$\left.{ }^{-1}\right]$ (@1.837) & 7601 & 10027 & 8372 & 9300 \\
\hline $\mathrm{V}_{0}\left[\mathrm{~L} \mathrm{~kg}^{-1}\right]$ & 601 & 923 & 706 & 704 \\
\hline
\end{tabular}


TKX-55 is one of the most thermally stable explosives (Fig. 6) ${ }^{[15-19]}$. The density, enthalpy of formation, nitrogen content, detonation velocity, and detonation pressure of TKX-55 are higher than those of the currently used heat-resistant explosives HNS and PYX. TKX-55 is insensitive to friction, and its sensitivity to impact and electrostatic discharge are comparable with those of HNS. In order to investigate experimentally the shattering effect of TKX-55, the Underwater Explosion Test was applied. Based on the collected data, the total energy as the sum of the primary shock wave energy (the brisance) and the bubble gas energy (the heaving effect) was calculated. The primary shock waves (and thus brisance) generated by TKX-55 and PYX are comparable in nature (Fig. 7). The first bubble collapse obtained for TKX-55 and PYX are also comparable. This indicates that both TKX-55 and PYX show similar action (heaving power) at longer distance from the point of initiation.
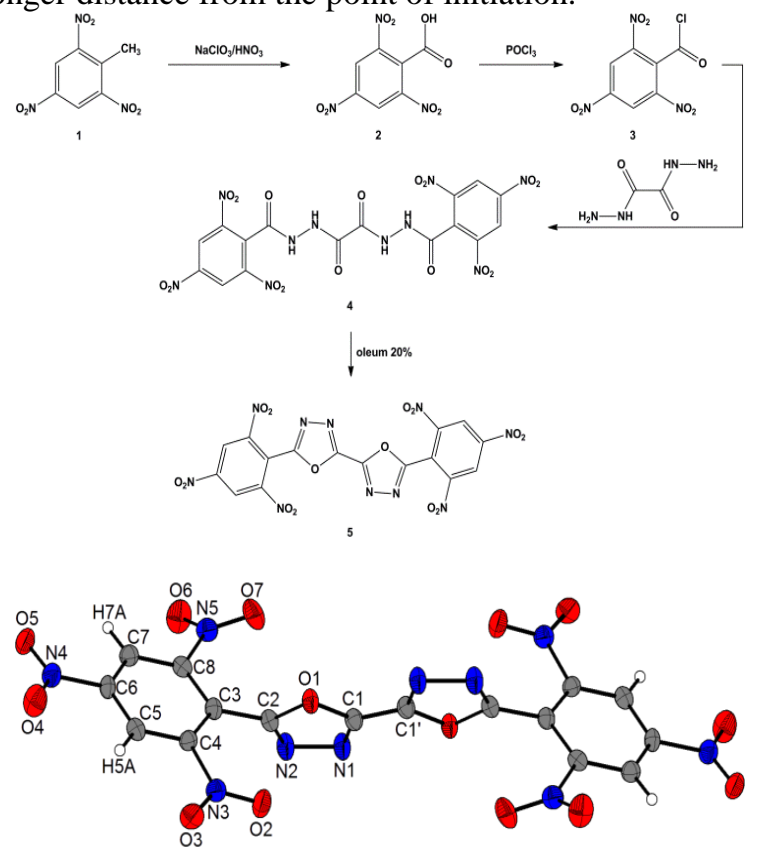

Fig. 6: Synthesis of TKX-55 (top) and molecular (X-ray) structure of TKX-55 (5) (bottom).

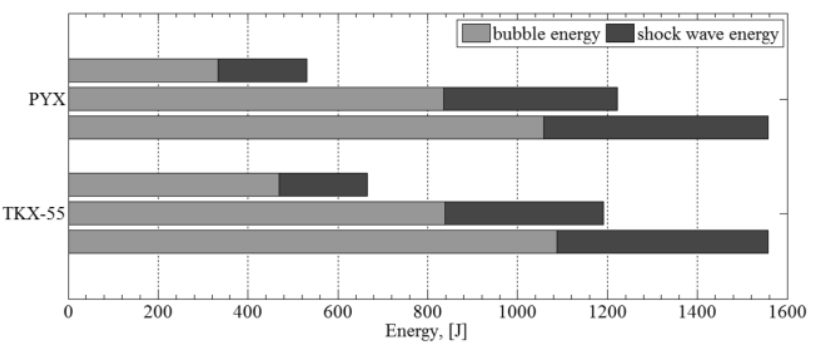

Fig . 7: Total energies $(E)$ generated in water by PYX and TKX-55 (0.2 g, 0.5 g, 0.7. g).

Therefore, further investigations into the performance of TKX-55 in shaped charge applications were undertaken (Fig. 8). The investigations focused on the jet penetration capability of conical shaped charges filled with TKX-55 in comparison with other explosives which are currently used. The kinetic energy of the jet depends on the brisance of the explosive which is used.

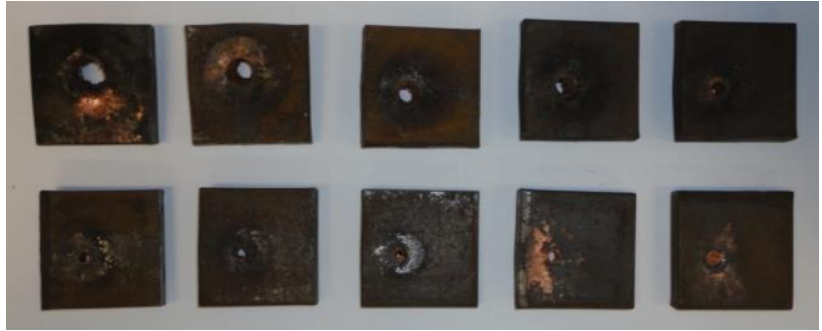

Fig. 8: Steel witness plates after firing the shaped charge filled with TKX-55.

To evaluate the explosive performance of TKX55 on a small scale, a Small-Scale Shock Reactivity Test was undertaken (SSRT). The SSRT measures the shock reactivity (explosiveness) of potential energetic materials, often below the critical diameter, without requiring a transition to detonation. TKX-55 was pressed into a perforated steel block. Initiation of the explosive under investigation was performed using a commercially available detonator (Figs. 9 and 10). The dent sizes were measured by filling them with fine powdered $\mathrm{SiO}_{2}$ and measuring the resulting weight. For comparison, the corresponding values for PYX and HNS are also given (Table 4).

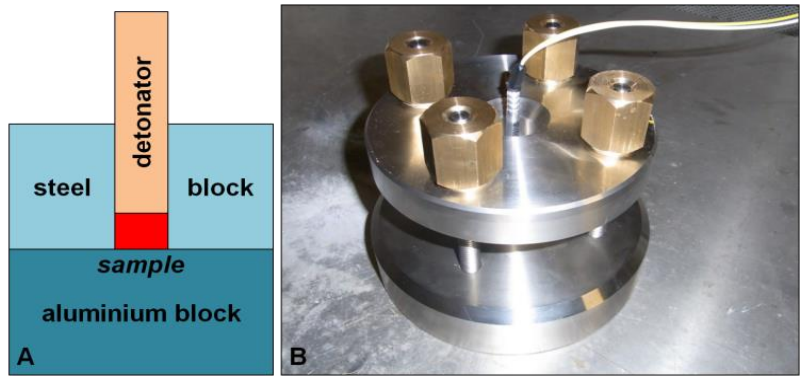

Fig. 9: Small Scale Shock Reactivity Test (SSRT): schematic drawing (A) (left), photograph of test set-up (B) (right).

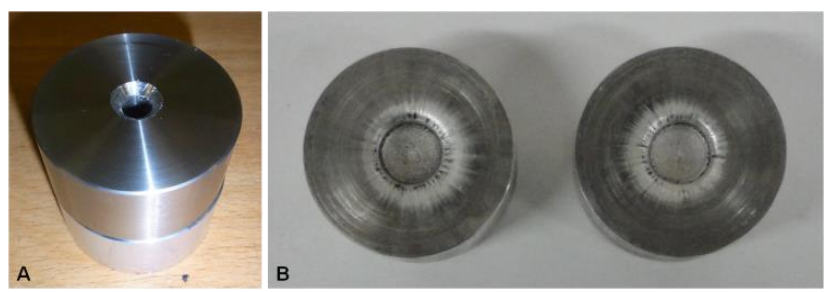

Fig. 10: The SSRT of TKX-55: aluminium block and the steel block filled with TKX-55 (A) (right) and dented aluminium blocks after initiation of the explosive using a commercial detonator (B) (right). 
Table 4: Results of the SSRT for PYX, HNS

\begin{tabular}{lccc}
\hline & PYX & HNS & TKX-55 \\
\hline $\mathrm{m}_{\mathrm{Ex}}{ }^{[\mathrm{a}]}[\mathrm{mg}]$ & 474 & 469 & 496 \\
$\mathrm{mSiO}_{2}{ }^{[\mathrm{b}]}[\mathrm{mg}]$ & 637 & 672 & 641
\end{tabular}

[a] Mass of the explosive : $\mathrm{m}_{\mathrm{E}} \mathrm{x}=\mathrm{Vs} \cdot \rho \cdot 0.95,(\mathrm{Vs}=284$ $\mathrm{mm}^{3}$ ).

[b] Mass of $\mathrm{SiO}_{2}$.

Double-base propellants (made by the extrusion or powder casting techniques) are used in anti-tank rockets or missiles and in some tactical missiles. Their main advantage is that they produce a minimum amount of smoke (smoke is produced only from a small amount of additives). Research is also on-going with the aim of finding new energetic ingredients for high-performance smokeless rocket propellants. Two promising candidates are TNC$\mathrm{NO}_{2}$ (2,2,2-trinitroethyl-nitrocarbamate, 2) ${ }^{[20,21]}$ and BTOx (bistrinitroethyl oxalate, 1) (Fig. 11 and Table 5) ${ }^{[22]}$.<smiles>O=C(O)COC(=O)C(=O)OCC([O-])[N+]([O-])([O-])[O-]</smiles><smiles>O=C(N[N+](=O)[O-])OCC([N+](=O)[O-])([N+](=O)[O-])[N+](=O)[O-]</smiles>

Fig. 11: Molecular structures of and BTOx (bistrinitroethyl oxalate, 1) (left) and TNC-NO $(2,2,2$-trinitroethyl-nitrocarbamate, 2) (right).

Table 5 : Calculated rocket performance parameters of BTOx and TNC- $\mathrm{NO}_{2}$

\begin{tabular}{|c|c|c|}
\hline & BTOx & $\mathrm{TNC}-\mathrm{NO}_{2}$ \\
\hline Formula & $\mathrm{C}_{6} \mathrm{H}_{4} \mathrm{~N}_{6} \mathrm{O}_{16}$ & $\mathrm{C}_{3} \mathrm{H}_{3} \mathrm{~N}_{5} \mathrm{O}_{10}$ \\
\hline Molecular Mass $\left[\mathrm{g} \mathrm{mol}^{-1}\right]$ & 416.1 & 269.1 \\
\hline IS [J] & $10[1]$ & $10[1]$ \\
\hline $\mathrm{FS}[\mathrm{N}]$ & $>360[1]$ & $96[1]$ \\
\hline $\operatorname{ESD}[\mathrm{J}]$ & $0.7[1]$ & $0.1[1]$ \\
\hline $\mathrm{N}[\%]$ & 20.2 & 26.0 \\
\hline$\Omega\left(\mathrm{CO}_{2}\right)[\%]$ & +7.7 & +14.9 \\
\hline $\mathrm{T}_{\text {m.p. }}\left[{ }^{\circ} \mathrm{C}\right]$ & 115 & 109 \\
\hline $\mathrm{T}_{\text {dec. }}\left[{ }^{\circ} \mathrm{C}\right]\left(\mathrm{DSC} @ 5^{\circ} \mathrm{C} / \mathrm{min}\right)$ & 186 & 153 \\
\hline$\rho\left[\mathrm{g} \mathrm{cm}^{-3}\right](@ 298 \mathrm{~K})$ & $1.84(298 \mathrm{~K})$ & $1.73(298 \mathrm{~K})$ \\
\hline$\Delta_{\mathrm{f}} H^{\circ}\left[\mathrm{kJ} \mathrm{mol}^{-1}\right]$ & -688 & -366 \\
\hline$\Delta_{\mathrm{f}} H^{\circ}\left[\mathrm{kJ} \mathrm{kg}^{-1}\right]$ & -1576 & -1277 \\
\hline$I_{\mathrm{sp}}[\mathrm{s}](\text { neat })^{\mathrm{a}}$ & 231 & 226 \\
\hline 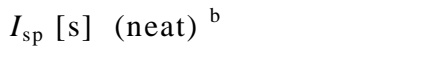 & 293 & 284 \\
\hline$I_{\mathrm{sp}}[\mathrm{s}]^{\mathrm{a}, \mathrm{c}}$ & 250 & 253 \\
\hline$I_{\mathrm{sp}}[\mathrm{s}] \mathrm{b}, \mathrm{c}$ & 324 & 328 \\
\hline
\end{tabular}

a- $70 \mathrm{bar} / 1 \mathrm{bar}$, isobaric combustion, equilibrium to throat and frozen to exit

b- 70 bar, 1 mbar, isobaric combustion, equilibrium to throat and frozen to exit

c- $50 \%$ oxidizer, $50 \%$ NC (13.15) 
Primary explosives such as lead azide and lead styphnate mostly contain toxic ingredients which have to be replaced. A new candidate that shows high potential, potassium 1,1'-dinitramino-5,5'bistetrazolate (K2DNABT), was synthesized by a sophisticated synthetic procedure based on dimethylcarbonate and glyoxal. K2DNABT combines good thermal stability with the desired mechanical stability (Fig. 12) ${ }^{[23,24]}$. Owing to its high heat of formation (326 kJ mol-1) and density (2.11 g cm-3), impressive values for its detonation velocity (8330 m s-1) and pressure (311 kbar) were computed. Its superior calculated performance output was successfully confirmed and demonstrated by different convenient energetic test methods (Table 6).

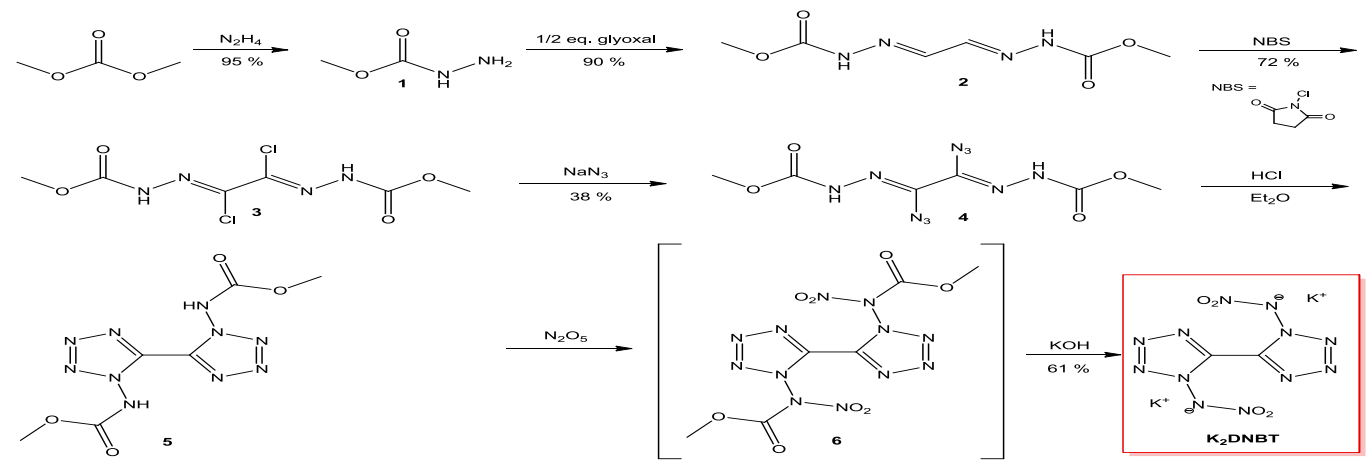

Fig. 12 : Synthesis of K2DNABT

Table 6: Energetic properties of K2DNABT in comparison with LA

\begin{tabular}{|c|c|c|}
\hline & LA & K2DNABT \\
\hline Formula & $\mathrm{N} 6 \mathrm{~Pb}$ & $\mathrm{C} 2 \mathrm{~K} 2 \mathrm{~N} 12 \mathrm{O} 4$ \\
\hline $\mathrm{FW} / \mathrm{g}$ mol-1 & 291.3 & 334.3 \\
\hline IS / J & $2.5-4$ & 1 \\
\hline $\mathrm{FS} / \mathrm{N}$ & $0.1-1$ & 5 \\
\hline $\mathrm{ESD} / \mathrm{J}$ & $<0.005$ & 0.003 \\
\hline $\mathrm{N} / \%$ & 28.9 & 50.3 \\
\hline$\Omega / \%$ & -11.0 & -4.8 \\
\hline TDec. $/{ }^{\circ} \mathrm{C}$ & ca. 315 & 200 \\
\hline$\rho / g \mathrm{~cm}-3$ & 4.8 & 2.172 \\
\hline$\Delta \mathrm{fHm}^{\circ} / \mathrm{kJ}$ mol-1 & 450.1 & 326.4 \\
\hline$\Delta \mathrm{fU}^{\circ} / \mathrm{kJ} \mathrm{kg}-1$ & 1574.9 & 1036.1 \\
\hline \multicolumn{3}{|l|}{ EXPLO5 6.01} \\
\hline$-\Delta \mathrm{ExU}^{\circ} / \mathrm{kJ} \mathrm{kg}-1$ & 1569 & 4959 \\
\hline Tdet / K & 3401 & 3424 \\
\hline PCJ / kbar & 338 & 317 \\
\hline VDet. / $\mathrm{m} \mathrm{s}-1$ & 5920 & 8330 \\
\hline Vo / L kg-1 & 252 & 489 \\
\hline
\end{tabular}




\section{CONCLUSION}

Future research will lead to even more powerful, high-nitrogen-high-oxygen explosives with enhanced and superior detonation parameters which are necessary to fulfil the lethality requirements of all forces. New energetic materials will provide a vastly increased energy content in comparison with RDX, and up to several times the energetic performance. In addition, these materials will have a high energy density with a high activation energy.

With these capabilities, it will be possible to develop new applications for energetic materials and vastly improve the performance of current munitions. The increased performance of the next generation of energetic materials will enable the same strategic goals to be met, but with fewer munitions and less energetic material. The increase in the energy output will be harnessed in munitions that require only a fraction of the amount of energetic material to deliver the same payload or thrust profile. This will allow engineers to put energetic materials in munitions that have never had them before.

Further areas of energetic materials research at LMU are:

- High Explosives (HEDM, RDX replacements)

- Lead-free Primary Explosives

- High Oxidizers (HEDO)

- Smokeless double-base rocket propellants

- Nitrogen-rich Gun Propellants

- Visible Pyrotechnical Compositions and Smokes

- Ingredients for Decoy Flares (MTV)

- NIR Illuminants

- Agent Defeat Weapons (ADW)

- Synthesis in flow / micro reactors

- Disruptive Energy from metastable polymorphs

\section{ACKNOWLEDGEMENTS}

Financial support of this work by the LudwigMaximilian University of Munich (LMU), the Office of Naval Research (ONR) under grant no. ONR.N00014-16-1-2062, and the Bundeswehr Wehrtechnische Dienststelle für Waffen und Munition (WTD 91) under grant no. E/E91S/FC015/CF049 is gratefully acknowledged. The authors acknowledge collaborations with Dr. Mila Krupka (OZM Research, Czech Republic) in the development of new testing and evaluation methods for energetic materials and with Dr. Muhamed Suceska (Brodarski Institute, Croatia) in the development of new computational codes to predict the detonation and propulsion parameters of novel explosives. We are indebted to and thank Drs. Betsy M. Rice, Jesse Sabatini and Brad Forch (ARL, Aberdeen, Proving Ground, MD) for many inspired discussions.

\section{REFERENCES}

[1] T.M. Klapötke, Chemistry of High-Energy Materials, $3^{\text {rd }}$ edn., de Gruyter, Berlin/Boston, 2015.

[2] Structure and Bonding, Vol. 125/2007: High Energy Density Compounds, T. M. Klapötke (vol. editor), D. M. P. Mingos (series editor), Springer, Berlin/Heidelberg, 2007.

[3] Energetics in the rest of the world, T. M. Klapötke, J. Short in: Topics in Energetics Research Development, R. E. Kaczmarek (ed.), chapter 4, Calce, College Park, MD, 2013, pp 53 - 90.

[4] The Synthesis Chemistry of Energetic Materials, T. M. Klapötke, in: Energetics Science \& Technology in Central Europe, J. Short, R. Armstrong (eds.), Chapter 5, 2012, 57 - 72.

[5] Chemical Rocket Propulsion - A Comprehensive Survey of Energetic Materials, T. M. Klapötke, M. Kettner, part II, L. DeLuca (ed.), Springer, ISBN: 978-3-319-27746-2, 2017, $63-88$.

[6] A. Hammerl, T. M. Klapötke, H. Nöth and M. Warchhold, G. Holl, M. Kaiser, Inorg. Chem. 40 (2001) 3570 - 3575.

[7] N. Fischer, T. M. Klapötke, M. Reymann, J. Stierstorfer, Eur. J. Inorg. Chem. (2013) $2167-2180$.

[8] N. Fischer, D. Fischer, T. M. Klapötke, D. G. Piercey, J. Stierstorfer, J. Mater. Chem. 22 (2012) 20418 - 20422.

[9] T. M. Klapötke, T. G. Witkowski, Z. Wilk, J. Hadzik, Prop. Explos. Pyrotech. 41 (2016) 92 - 97.

[10] N. Fischer, T. M. Klapötke, A. Matecic Musanic, J. Stierstorfer, M. Sucesca, New Trende in Research of Energetic Materials, Part II, Pardubice, Czech Rep. (2013) $574-585$.

[11] V. K. Golubev, T. M. Klapötke, New Trends in Research of Energetic Materials, Czech Republic (2014) Vol. 1, pp. 220 - 227.

[12] V.K. Golubev, T. M. Klapötke, New Trends in Research of Energetic Materials, Czech Republic (2014) Vol. 2, pp $672-676$.

[13] W.-P. Zhang, F.-Q. Bi, Y.-S. Wang, Y.-F. Huang, W.-X. Li, C.-L. Wang, S. X. Zhao, Chinese J Expl. Prop. 38 (2015) $67-71$.

[14] D. Fischer, J. L. Gottfried, T. M. Klapötke, K. Karaghiosoff, J. Stierstorfer, T. G. Witkowski, Angew Chem. Int. Ed., 2016, 55, $16132-16135$.

[15] J. L. Gottfried, T. M. Klapötke, T. G. Witkowski, Prop. Expl. Pyrotech. 2017, 42, 353 - 359

[16] T. M. Klapötke, T. G. Witkowski, Chem PlusChem 81 (2016) 357-360.

[17] T. M. Klapötke, T. G. Witkowski, Prop. Expl. Pyrotech. 40 (2015) 366 - 373. 


\section{Engineering Science and Military Technologies}

Volume (2) - Issue (1) - 2018

[18] T. M. Klapötke, T. Witkowski, Prop. Expl

[19] T. M. Klapötke, T. G. Witkowski, Z. Wilk, J. Hadzik, Central Europ. J. Energ. Mat. 2016, 13(4), 821-837.

[20] Q. J. Axthammer, T. M. Klapötke, B. Krumm, R. Moll, S. F. Rest, Z. Anorg. Allg. Chem. 640 (2014) 76 - 83.

[21] Q. J. Axthammer, B. Krumm, T. M. Klapötke, J.Org. Chem. 80 (2015) 6329 - 6335.
Pyrotech, 2016, 41, $470-483$.

[22] T. M. Klapötke, B. Krumm, R. Scharf[, Europ. J. Inorg. Chem. (2016) 3086-3093.

[23] T. M. Klapötke, N. Mehta, Prop. Expl. Pyrotech. 39 (2014) 7 - 8.

[24] D. Fischer, T. M. Klapötke, J. Stierstorfer, Angew. Chem. 126 (2014) 8311 -8314; Int. Ed. 53 (2014) 8172 -8175. 